\title{
DO PALCO DAS (IN)DIFERENCCAS AOS BASTIDORES DA PÓS-MODERNIDADE: TEORIA HISTÓRICA E PRÁTICAS CONTEMPORÂNEAS
}

\author{
Cláudio Pellini Vargas* \\ Universidade Federal de Juiz de Fora (UFJF)
}

RESUMO: Na conturbada esteira epistemológica contemporânea, o presente ensaio crítico tem por objetivo problematizar o discurso de pesquisadores acadêmicos que se sustentam no pensamento relativista pós-moderno em seu estado mais dissimulado e radical. Na sua estrutura, o trabalho contextualiza historicamente o campo "pós" à luz das ideias de Perry Anderson. Num segundo momento, apresenta relatos vivenciados em distintas universidades brasileiras, sendo os quais iluminados e discutidos, essencialmente, pelas teorias de Terry Eagleton e David Harvey. Em síntese, argumenta-se na conclusão que as teorizações radicais "pós-modernas" tendem a se afastar da ideia de "respeito às diferenças", ao fomentar as desconstruções epistemológicas que encaminham teorias, práticas e valores, na direção de uma homogeneização "carismática", mas niilista e superficial. Palavras-chave: Epistemologia. Racionalidade. Pós-modernidade. Diferenças.

FROM THE STAGE OF (IN)DIFFERENCES TO THE BACKSTAGE "POSTMODERNITY": HISTORICAL THEORY AND CONTEMPORARY PRACTICES

ABSTRACT: In the turbulent contemporary epistemological mat, the present essay aims at problematizing post-modern discourses of academic researchers that support that the relativistic thought in its most underhanded and radical state. In its structure, the paper contextualizes the "postmodern" field using Perry Anderson. Ina second moment, we present reports experienced in different Brazilian universities, which are illuminated mainly by Terry Eagleton and David Harvey's theory. In summary, this work argues that radical "postmodern" theories move away from the idea of "respect for differences" by encouraging epistemological deconstructions that lead theories, practices and values toward a charismatic homogenization, but nihilistic and superficial.

Keywords: Epistemology. Rationality. (Post)Modernity. Difference.

http://dx.doi.org/10.1590/0102-4698136676

* Doutorando em Educação pelo Programa de Pós-graduação em Educação (PPGE) da Universidade Federal de Juiz de Fora (UFJF). Bolsista da Fundação de Amparo à Pesquisa do Estado de Minas Gerais (FAPEMIG). Pesquisador membro dos grupos de pesquisa: A Internacionalização do Campo do Currículo: condições, desafios e possibilidades de um novo paradigma da Universidade Católica de Petrópolis (UCP); e História da Educação Física e do Esporte, da Universidade Federal de Juiz de Fora (UFJF). Email: prof.pellini@yahoo.com.br 


\section{CONSIDERAÇÕES INICIAIS}

O Renascimento está morto, o Iluminismo está morto, a racionalidade está morta, o marxismo está morto, o movimento da classe trabalhadora está morto, o estruturalismo está morto... e eu já começo a passar mal.

(Adaptado de Neil Smith)

Dizia Max Weber, referindo-se à Modernidade, que o destino de uma época que se alimentou quase que exclusivamente dos frutos do conhecimento, é ter que admitir que as concepções gerais da vida não podem ser meros produtos do empirismo crescente, e que os mais elevados ideais, estes que nos movem com maior intensidade, com maior vigor, sempre são formados apenas na luta com outros ideais, os quais são tão sagrados para os outros quanto os nossos são para nós. Eu tenho que concordar com Weber.

Assim posto, apresento neste texto uma crítica contundente. Trata-se de uma análise do relativismo pós-moderno, principalmente sobre algumas interpretações de Nietzsche, as quais influenciaram radicalmente alguns pensadores contemporâneos. Tais influências, ao longo das últimas décadas, disseminaram críticas discursivas às formas modernas da racionalidade, às suas prepotências, às normas, valores... e muitas vezes por meio de curiosas abstrações, destacadas principalmente nas concepções sobre diferenças.

Segundo vários estudos (ANDERSON, 1999; EAGLETON, 2011; HARVEY, 2012; LIPOVETSKY, 1989; MOREIRA, SILVA, 2008), existe uma noção teórica "pós-moderna" que leva às últimas consequências os pressupostos de inexistência da "verdade", pelo fato de causarem uma sensível reviravolta nas noções epistemológicas da modernidade. Para essa tendência, a modernidade faliu e deve ser superada. Nesse grupo, enquadram-se diversos estudos pósestruturalistas, pós-críticos de gênero, das diferenças, da sexualidade, do multiculturalismo, da teoria queer, etc.

Isso posto, sustentarei a ideia pós-moderna nas palavras de Eagleton (1998, p. 7):

Pós-modernidade é uma linha de pensamento que questiona as noções clássicas de verdade, razão, identidade e objetividade, a ideia de progresso ou emancipação universal, os sistemas únicos, as grandes narrativas ou os fundamentos definitivos de explicação. [...] vê o mundo como contingente, gratuito, diverso, instável, imprevisível, um conjunto de culturas ou interpretações desunificadas gerando certo grau de ceticismo em relação à objetividade da verdade, da história e das normas, em relação às idiossincrasias e a coerência de identidades. 
Creio poder afirmar que nenhum tipo de pensamento é tão mal visto na contemporaneidade como a ideia de "verdade absoluta". As sensações advindas do termo exprimem autoritarismo, prepotência, dogmas etc. Particularmente, julgo ser um erro acreditar que as verdades não existam, pois só não sabemos mesmo onde algumas delas estão. Ademais, pensar a verdade apenas como absoluta me parece uma característica mais peculiar dos grupos "pós" do que dos estudos críticos, pois quando rejeitam as sensações descritas que o termo apresenta, acabam por negar pontos que podem ser realmente verdadeiros. Quero dizer: jogam tudo fora de uma só vez.

Nessa esteira, apresento este ensaio crítico com quatro relatos de minha trajetória acadêmica, problematizando ideias pós-modernas mais radicais. $\mathrm{Na}$ observação de variadas práticas relativistas, tive a sensação de que democracia ou liberdade são expressões inseparáveis de termos como abstração e ceticismo. Percebi ainda que algumas fronteiras entre alta e baixa cultura, entre o racional e o irracional, entre o belo e o vulgar, realmente não mais existem para alguns. $\mathrm{Na}$ condição de pesquisador, sobraram-me questionamentos, e dentre eles destaco: vamos lutar pelo quê, enquanto sociedade, num cenário pós-moderno que tende ao niilismo?

As reflexões partem de um pressuposto principal: a dinâmica de globalização do mundo capitalista somada ao sistema de controle e a necessária existência de regulações e políticas me parecem "narrativas" difíceis de serem negadas na contemporaneidade, o que me impulsiona a problematizar com maior rigor as "vontades de potência" dos defensores filosóficos de Nietzsche e da pós-modernidade.

\section{A DESCRIC̣ÃO DA ANÁLISE E DOS OBJETIVOS}

Este ensaio reflexivo é sustentado por quatro relatos articulados com a teoria escolhida e nasceu de minha observação e interpretação de práticas pedagógicas e de debates vivenciados em minha trajetória acadêmica em universidades distintas. Nos contextos citados, minha preocupação central foi o processo pedagógico envolvido pela ideia pós-moderna, a sua carga ideológica e as implicações que delas emergem. Trata-se de uma reflexão ensaística que tem por objetivo central, contribuir com debate epistemológico no cenário educacional. Minha intenção é revelar criticamente práticas pedagógicas "estranhas", as quais se apropriam de teorias relativistas (talvez com o propósito de validar ideologias). 
Todos os relatos narram a pós-modernidade vivenciada dentro de universidades e foram caracterizados por minha interação com os envolvidos e com as situações descritas. Este é ponto mais significativo do trabalho, pois descrevo o niilismo em ação. Busco problematizar situações que surgiram no decorrer das experiências e do convívio, por isso, cumpre-me enfatizar que nenhum dos sujeitos envolvidos sabia sobre qualquer análise que eu realizava, o que tende a revelar maior espontaneidade de suas práticas e de seus pensamentos. Atento para uma descrição genérica e mais estrutural dos momentos, sem descrever todos os detalhes, ou mesmo todas as situações, visando assim contribuir com as reflexões também em outros contextos e preservando a ética acadêmica. Destaco que toda e qualquer identificação de sujeitos e espaços foi cuidadosamente suprimida do trabalho.

$\mathrm{Na}$ estrutura do texto, apresento primeiramente uma análise histórica da pós-modernidade, sustentada por Perry Anderson (1999). Num segundo momento, apresento quatro relatos, os quais são atravessados por categorias de análise que identificam as ideias com as quais os sujeitos envolvidos apresentaram significativas relações: (1) abstração; (2) ironia; (3) poder; (4) teoria; (5) estética; (6) cultura; (7) ceticismo, entre outras que podem ter escapado à minha percepção. Em terceiro, apresento uma crítica sobre alguns fragmentos teóricos da literatura relativista e destaco as características mais fundamentais da pós-modernidade. As interpretações das discussões são iluminadas, essencialmente, pelas ideias de Terry Eagleton e David Harvey, as quais abordam o impacto e a difusão ideológica do pensamento pós-moderno. Por fim, argumento que as teorias "pós" tendem a desvalorizar as "diferenças" por meio de uma tentativa de homogeneização niilista.

\section{CONSIDERACִÕES HISTÓRICAS E POLÍTICAS}

Realizo inicialmente uma análise da construção do pensamento pós-moderno inserida numa breve descrição de nossa história recente ao longo do século XX e para tal, sigo os parâmetros de Anderson (1999). Para o autor, a ideia "pós" foi assinalada e reconhecida, primeiramente, no movimento artístico da década de 1930, mas no mundo hispânico, quero dizer, longe dos salões americanos ou europeus. Ressalto que a ideia modernista, aqui exposta num contexto artístico, evidenciava um caráter de emancipação cultural dos países hispânicos face à Espanha, inspirada pelo romantismo, parnasianismo e simbolismo franceses anteriores, dentro de um embate literário ocorrido no Peru nos confins do século XIX, mais precisamente em 1890. 
Segundo Anderson (1999, p. 9-10), o termo pós-modernismo

\begin{abstract}
surgiu [...] uma geração antes do seu aparecimento na Inglaterra ou nos Estados Unidos. Foi [...] Frederico Onís, quem imprimiu o termo postmodernismo. Usou-o para descrever um refluxo conservador dentro do próprio modernismo: a busca de refúgio contra o seu formidável desafio lírico num perfeccionismo do detalhe e do humor irônico, em surdina, cuja principal característica foi a nova expressão autêntica que concedeu às mulheres.
\end{abstract}

Tratava-se de um estilo estético no qual as ideias oriundas da modernidade, ou mesmo dos movimentos artísticos renascentistas que precederam a racionalidade, pareciam não mais "dar conta" do alcance que determinados artistas da época pretendiam. A ideia pós-moderna criada por Onís não teve grande impacto imediato, aparecendo no cenário intelectual apenas vinte anos mais tarde, significando mais uma categoria de época do que um estilo estético.

Assim iniciada, ao longo do século XX a ideia filosófica "pós" ganhou expressão e maior significado (mesmo sendo um termo que, ironicamente, gera uma compreensão da inexistência de significados), passando a compor os discursos de variados intelectuais. Dentre eles, Michel Foucault ${ }^{1}$ parece mesmo ter sido o que teve maior relevância para o cenário acadêmico nos campos da Filosofia, da Política, da Sociologia e da Educação. Agregue-se a isso, toda conjuntura políticosocial do ocidente, quero dizer, em diversas sociedades, como EUA, França, Itália, Espanha, Portugal, Brasil, Chile, entre outras, havia latente uma ideia de contestação e subversão às ordens governamentais vigentes. A modernidade, então, parecia mesmo revelada também na política, denunciada como incapaz de cumprir com suas promessas.

Pelo fato das ideias oriundas da fase moderna do pensamento humano parecerem mais enfraquecidas diante desse cenário, desencadearam-se, naturalmente, movimentos reacionários às propostas "pós". Muitos intelectuais - talvez Habermas seja o mais representativo - continuavam acreditando que era possível sustentar posicionamentos de centralidade social tendo como base as ideias da racionalidade, de projeto histórico, de equilíbrio e de equidade nascidas no berço do Iluminismo do século XVII e consolidadas no ideário da Revolução Francesa. A modernidade, assim, em contraponto com a pós-modernidade, mostrou-se mesmo um tema repleto de caminhos a serem explorados. Contudo, creio ser seguro afirmar que as controvérsias dessa discussão, nos dias atuais, já não são mais tão obscuras quanto eram cerca de duas ou três décadas atrás. Continuemos...

Considerando um segundo pressuposto fundamental que também me move na reflexão, o da dificuldade (talvez impossibilidade) 
em investigar a "diferença" ignorando política e ideologia, advogo que intelectuais marxistas no início dos anos de 1990, inconformados com a dinâmica global que surgia diante de seus olhos - quero dizer, com a derrocada da esquerda ocorrida na Europa da "Cortina de Ferro" e com a vitória dos direitos humanos - se agarraram quase que desesperadamente no niilismo de Nietzsche e em seus herdeiros. Preferiram os blefes oportunos da ideia de "tolerância a qualquer custo", do que insistir na utopia inalcançável (ou mesmo admitir uma vontade silenciosa de "liberalismo"). Será esse grupo aquele que David Harvey (2012, p. 319) denomina por "nova esquerda", ao destacar a crise do materialismo histórico?

A nova esquerda preocupava-se com uma luta para libertar-se das algemas duais da política da velha esquerda, particularmente em sua representação por partidos comunistas tradicionais e pelo marxismo "ortodoxo", e dos poderes repressivos do capital corporativo e das instituições burocratizadas [...]. Ela via a si mesma, desde o começo, como uma força cultural e político-econômica, tendo ajudado a produzir a virada para a estética que o pós-modernismo representava.

Essa forma de agir, todavia, gerou resultados que não foram vislumbrados. Harvey continua e explica que a entrada na política cultural era mais adequada ao anarquismo e ao liberalismo do que ao marxismo tradicional, levando a "nova esquerda" a combater atitudes e instituições mais tradicionalistas da classe trabalhadora. Ela se envolveu com vários movimentos sociais - recentes na época - e que eram eles mesmos causadores de uma desintegração da política da velha esquerda. Nas palavras de autor (2012, p. 319-320):

$\mathrm{Na}$ medida em que [a velha esquerda] era, na melhor das hipóteses, passiva, e, na pior, reacionária (no tratamento das questões de raça e de gênero, da diferença, e de problemas dos povos colonizados e das minorias reprimidas e das questões ecológicas e estéticas), algum tipo de mudança política da espécie proposta pela nova esquerda por certo se justificava. Mas, ao fazer esse movimento, a nova esquerda tendia a abandonar a sua fé tanto no proletariado como instrumento de mudança progressista, como no materialismo histórico enquanto modo de análise.

Assim, me parece ter ocorrido uma redistribuição dos desertores marxistas dentro do campo "pós". Seria algo como uma espécie de "diáspora da esquerda", difundida sob muitos rótulos distintos de análise e interrogação do mundo: pós-estruturalistas, pós-críticos, pós-colonialistas, pós-industrialistas, pós-metafísicos ou qualquer outro que ainda venham a inventar neste novo espaço de disputa, visto que nos demais campos epistemológicos e artísticos, o "relativismo" já se apresentava bem mais confiante e entusiasmado desde os anos de 1960. Harvey (2012, p. 9), em alusão semelhante, 
diz que "uma vez vinculado com o pós-estruturalismo, com o pósindustrialismo e com todo um arsenal de outras 'novas ideias', o pós-modernismo dava a impressão crescente de uma poderosa configuração de novos sentimentos e pensamentos", sendo compreendido por alguns como paradigma emergente.

Mas foi aí mesmo, nessa década, que o termo parece ter adquirido parte de sua significação pejorativa. A juventude ocidental de "excluídos" da história, cerceada por diversidade cultural, euforia e alucinógenos, desinteressada por deveres e focada em direitos civis, logo encontrou abrigo na literatura "pós".

[...] essa literatura produziria um cruzamento de classes e uma mistura de gêneros, repudiando as ironias e formalismos modernistas, para não falar nas distinções entre elevado e inferior, numa volta desinibida ao sentimental e burlesco. Em 1969, [o pós-moderno podia ser visto] no seu apelo à emancipação vulgar e à liberação dos instintos, como um eco prudentemente despolitizado da insurreição estudantil da época [...]. (ANDERSON, 1999, p. 19)

Nessa esteira de revolta e oportunismo é que o discurso científico, já apresentando certa fragilidade por uma série de fatores, também se abriu para as confusões "pós", fundamentalmente causadas

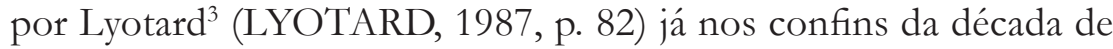
1970. O mentor da falácia, ao perceber que a racionalidade científica claudicava - pelo fato de seus representantes reduzirem "verdades" ao império do capital, ao controle do mercado e ao desempenho técnico, agregando-se ainda os paralogismos antecipados por Nietzsche no campo filosófico desde os confins do século XIX, as teorias psicanalíticas freudianas que fragmentaram a consciência na primeira metade do século XX, e ainda, por Heisenberg e Einstein, que abalaram as estruturas da Física - não hesitou também em relativizar sobre a credibilidade da razão. Mas será muito afirmar que, para se atacar a racionalidade, foi necessária a própria racionalidade? Por mais que houvesse certa fundamentação em parte das argumentações elencadas anteriormente, já que a modernidade e o pensamento racionalista precisam sim ser problematizados, a radicalidade do pensamento de Lyotard, ao contrário, se equivocou por gerar uma espécie de "contrato temporário em todas as áreas da espécie humana" (ANDERSON, 1999, p. 33), tornando-se a marca fundamental do pós-moderno e da vulgarização, seja para simpatizantes ou opositores epistemológicos. Foi uma guinada errada. Se hoje, é comum ouvirmos chavões do tipo: "Nietzsche matou Deus, mas coube a Freud fechar o caixão", me arrisco a ironizar que Lyotard e Deleuze "cavaram uma cova tão profunda no enterro que acabaram por dar a volta 
completa, desembocando no mesmo lugar". Impunha-se a partir daí a desconstrução homogeneizante como alternativa única. É como se houvesse quase um pavor, o qual movia o pós-moderno a tentar esconder as diferenças que a racionalidade verdadeiramente destacava. Já em meados dos anos de 1980, acontece uma espécie de acoplamento fundamental entre a pós-modernidade e a objetividade da ordem capital. Para Martins (2009, p. 69), existe mesmo uma tendência contemporânea de

quebra de certas barreiras culturais que tendem à massificação de manifestações e unificação das subjetividades. Entretanto, não é verdade que tal tendência possua uma força própria nem seja algo espontâneo, já que existe um número significativo de intelectuais e sujeitos políticos coletivos a serviço do capital que vem se dedicando a globalizar o mundo através de inúmeros mecanismos: pelas artes, pela moda, pela mídia.

Não mais como estética ou epistemologia, o "pós" se transformara num símbolo cultural no/do modo de produção vigente. O termo "sociedade de consumo", amplamente utilizado nas ciências sociais contemporâneas, serviu como ferramenta de mensuração do futuro. $\mathrm{O}$ período era marcado pelo capitalismo multinacional, quero dizer, explosão tecnológica como lucro; grandes corporações instaladas em países emergentes, nos quais se pagavam baixos salários pela mesma mão-de-obra; intensos diálogos internacionais instigando transposições de fronteiras e cooperação; informação e comunicação como primordiais à continuidade do progresso. A modernidade parecia tangenciar seus próprios sonhos e promessas "técnicas". Abria-se um novo horizonte às sociedades capitalistas do primeiro mundo, uma perspectiva ainda "virgem", e na qual a ideia de cultura "pós" se ancorou à economia. Para Anderson (1999, p. 67),

A cultura [pós] nesse sentido, como inevitável tecido na vida do capitalismo avançado, é agora a nossa segunda natureza. Enquanto o modernismo extraía seu propósito e energias da persistência do que ainda não era moderno, do legado de um passado ainda pré-industrial, o pós-modernismo é a superação dessa distância, saturação de cada poro do mundo com o soro do capital.

Ao considerar então, a anterior agitação dos anos de 1960, que despiu o tradicionalismo de suas vestes, e que estava agora também purgada de muitos de seus radicalismos pelos filtros das derrotas políticas da década de 1970 em vários países, me parece elementar compreender que a sensibilidade pós-moderna perderia mesmo qualquer noção de história e creio que, nesses argumentos, possamos compreender um pouco melhor como a ideia de niilismo se fortaleceu, comprometendo 
sua possibilidade de "valorizar as diferenças". Formava-se aí, uma nova subjetividade coletiva que não mais temia aquele futuro apocalíptico que os mitos da modernidade técnica, fria e insensível costumavam vociferar, vistos até mesmo no cinema ${ }^{4}$; e não havia também qualquer afeição por um passado que, numa visão mais ampla, só trazia frustrações. $\mathrm{O}$ resultado, o qual pode ser visto tranquilamente nos dias de hoje em muitos campos da vida - para muito além dos relatos acadêmicos que destacarei - é a superficialidade do sujeito.

Harvey (2012) corrobora e afirma a ocorrência de mudanças abissais nas práticas culturais, bem como político-econômicas desde mais ou menos 1972, mas que quando confrontadas com a base da acumulação capitalista, mostram-se mais como transformações da aparência superficial do que como sinais do surgimento de alguma sociedade pós-capitalista ou mesmo pós-industrial inteiramente nova.

\section{OS RELATOS: A “PÓS-MODERNIDADE EM AĈ̣̃O”}

O primeiro relato narra meu contato inicial com o pensamento "pós", o qual ocorreu em minha formação na graduação. Eu cursava uma "disciplina de verão", termo comum em meados dos anos noventa. A matéria chamava-se Didática, havia alunos de variados cursos de licenciatura e a professora demonstrava comprometimento com seu trabalho. Ao final de cinco semanas, tínhamos que apresentar trabalhos sobre determinados conteúdos na forma de seminários didáticos.

Entre muitos interessantes, fossem inovadores ou tradicionais, o mais impactante foi o de uma dupla que vivia em silêncio durante as aulas. Não me lembro de vê-los interagir com a turma ou sequer de ter escutado qualquer um dos dois falar. Em sua apresentação final para a avaliação da disciplina, não foi diferente. Com um aparelho de som, tocaram músicas do Pink Floyd mixadas a algumas falas de Jim Morrison, vocalista da banda The Doors (sucesso do rock "alternativo" dos anos 1970), durante os quase trinta minutos da apresentação. Ao ligarem o som, escreveram no quadro: "Todo discurso é fascista!". A seguir, deitaram-se no chão no meio da sala, e ali permaneceram imóveis - e em total silêncio - até o fim da fita cassete.

É claro que foi estranho - e foi até divertida a ansiedade que eles causaram em parte da turma. Eagleton (2011) ressalta que, nos velhos tempos, o rock era uma distração que distanciava os jovens dos estudos. Contudo, reforça que hoje pode bem ser o "conteúdo" que se estuda em uma sala de aula. "As questões sobre intelectualidade já não são mais um assunto tratado em torres de marfim [...]" (EAGLETON, 2011, p. 15). Entretanto, é necessário refletir: o casal permaneceria em 
silêncio durante seu curso inteiro na graduação? Eles lecionariam em silêncio nas escolas em que, porventura, tentassem ingressar? Que conteúdo foi proposto na referida apresentação? Em que medida o radicalismo da postura "pós" de permanecer em silêncio era mais importante do que pensar uma alternativa didática de se levar um "conhecimento mais concreto", ou mesmo que se explorassem as implicações da abstração apresentada ao grupo que assistia? Em que medida impedia-se a comunicação necessária à heterogeneidade da turma? Em sua crítica, Harvey (2012, p. 315) explica que a "primeira linha de defesa ["pós"] é a fuga para um tipo de silêncio exaurido, blasé ou encouraçado [...]". Tudo parece estar nutrido de um sentido único e intratável... fora do controle individual e coletivo.

Ressalto minha intenção de destacar criticamente as implicações das posturas pedagógicas analisadas. Sustento que a crítica tem a função não de descobrir verdades, mas de verificar validades dentro de um sistema coerente de signos. Ora, nós vivemos um tempo moderno por excelência, ainda que "líquido" (BAUMAN, 2001), temos divisão do trabalho, classes, regulações, avaliações e leis em geral. Sejam bons ou ruins para minorias ou maiorias, negociados ou não, o fato é que esses são signos contemporâneos que existem. Ainda que causem desigualdades e opressões a alguns grupos, podem trazer também segurança para outros. Para Eagleton (2011, p. 62), foi exatamente este "senso de um mundo claustrofobicamente codificado, administrado, bombardeado com signos e convenções de uma ponta a outra [que] ajudou a parir o estruturalismo, que investiga [...] os códigos ocultos que produzem significado humano". A crítica, assim, não é uma homenagem a um tipo de verdade, ela é a construção inteligível do tempo, e reitero aqui: um tempo ainda moderno por excelência.

Apresento assim, o segundo relato. Presenciei o pensamento relativista em uma aula, na qual a ideia "pós" foi representada pela informação objetiva de que "qualquer aluno poderia escrever o que quisesse na lousa e a qualquer momento". No início, a maioria dos neófitos pareceu não compreender bem, permanecendo em silêncio. Mas a partir da primeira escrita, muitos começaram a se levantar para "rabiscar" o quadro negro.

Entre inúmeras ironias, aforismos, palavras apresentadas de forma invertida, erros gramaticais propositais, expressões idiomáticas, visões múltiplas de mundo, chavões político-ideológicos, provocações entre os participantes, desenhos e piadas diversas, permanecemos na atividade por mais de uma hora, até o momento em que um participante arranhou e sujou o quadro com tinta vermelha, afixando 
(colando) também uma "estopa branca". A estranha intenção parecia representar uma espécie de "ferimento sangrando" na lousa - um material didático público - após a disputa por poder durante a prática. Ao fim da aula, nada mais foi explorado para além de um pertinente comentário docente: "Quais as implicações disso tudo?" Houve novo silêncio. Parecia haver um incômodo geral. Uma espécie de "malestar filosófico" que permanecia mais entre os sujeitos não adeptos do que aos familiarizados às ideias pós-modernas.

Questionando a pertinência da prática relatada, se teorizar significa refletir sistemática e minimamente sobre um pressuposto que nos orienta, suponho que ela continue muito necessária. Nesse sentido, encontra-se o oportuno alerta quanto à superficialidade da pós-modernidade em Anderson (1999, p. 132), afirmando que "a cultura do espetáculo gerou, naturalmente, sua própria ideologia. É o credo do pós-modernismo, descendente de Lyotard. Intelectualmente não é de grande interesse: uma mistura nada exigente de noções cujo resultado é pouco mais que uma tagarelice convencional".

Será que o mundo se resume a "discursos" e está sempre relacionado a "poder"? A diferença entre ciência e vida cotidiana, entre civismo e anarquia, continuam sendo marcas a serem mostradas aos estudantes? Respeitar e prezar pelo patrimônio público ainda significa cidadania? Creio que os docentes deveriam pensar seriamente nisso, principalmente depois que o relativismo passou a ganhar tamanho enfoque. Existe também uma cisão entre escola/universidade e senso comum que pode e deve ser problematizada - mas nunca negligenciada a qual é delineada claramente pelas capacidades de análise, interpretação, conceituação e desenvolvimento crítico. Parece que muitos alunos e docentes já não sabem mais o que isso significa. Agregue-se o fato de que, no contexto contemporâneo brasileiro marcado politicamente por um "escravismo assistencialista", jovens calouros chegam aos primeiros períodos do ensino superior com enormes dificuldades de leitura, escrita e praticamente incapazes de interpretar um texto.

Assim, me parece importante lembrar que um mínimo de educação e de construção no tecido social é fundamental nas instituições formativas. Seria como escreveu Gramsci (1986, p. 41) sobre Educação: "[...] certo dogmatismo é praticamente indispensável”. Em síntese, sustento que os conteúdos sistematizados - os conhecimentos objetivos e concretos que ultimamente são relativizados e substituídos por práticas "estranhas" - e que poderão levar os jovens para além de suas experiências prévias e cotidianas, são essenciais e não podem ser negligenciados na 
escola/universidade (YOUNG, 2011). Acrescento, porém, como Moreira (2010), que é necessário associar esse desenvolvimento dos conteúdos com os fenômenos culturais marcantes existentes na sociedade contemporânea, como a pluralidade cultural e a política de identidades, entendidos como paradigmas do reconhecimento.

Meu terceiro relato discorre sobre arte e estética. É sabido que os artistas também contribuem com a sociedade por meio de suas críticas, invenções, inspirações, criações, enfim, por muitas de suas "audácias". A história, tão negada pela pós-modernidade, revela desde os primórdios da civilização, profunda relação entre sensibilidade e lucidez, a qual pode ser legitimamente percebida - apenas como um exemplo - no período da Renascença. Entretanto, ao deparar-se com Nietzsche no século XIX, a trajetória da estética parece esbarrar na expropriação da racionalidade, revelando uma insuficiência do sujeito contemporâneo (COELHO, 2013), a qual pode ser observada em inúmeras interpretações simplistas.

No cenário pós-moderno parece emergir nova concepção artística: uma espécie de estética para "além do bem e do mal". Presenciei uma compreensão bastante intrigante em um encontro acadêmico, no qual foram expostas, por meio de um projetor de imagens, cenas de um artista contemporâneo que se autoflagelava com pequenas queimaduras e perfurações corporais. Para os ferimentos reais, ele utilizava um palito de fósforo - hora apagado, hora aceso - perfurado na pele; ele também se unia corporalmente a cadáveres de animais, em especial a cachorros, os quais ele mesmo fotografava, como também a todo o processo de mutilação dos bichos. Nesse exemplo, ele se utilizou do focinho e das orelhas de um cão dissecado, acoplando-os no próprio rosto. Assim, propunha imagens surreais - homem com cara de cachorro - acreditando retratar com sua obra uma relação entre a fragilidade do artista e a ferocidade do animal. Confesso lamentar a decadência das imagens assistidas que, para alguns, foi legitimada como arte contemporânea.

Como Eagleton (1998) bem registra, a pós-modernidade apresenta um estilo de cultura que reflete essa mudança memorável que vivemos hoje, por meio de expressões artísticas superficiais, descentradas, infundadas e que obscurecem as fronteiras entre o belo e a experiência cotidiana. Anderson (1999) completa e diz que a ideia de ruptura entre o moderno e o pós-moderno não apenas chegou primeiro ao campo da arte, mas foi aí que teve seu reflexo mais drástico, gerando teorias das mais "ambiciosas" sobre o futuro da estética. Soa-me mesmo irônico acreditar que o pensamento "pós" crie tanto fetiche em torno da diferença, dado que seu próprio impulso é "apagar distinções entre verdade e ficção, história e fábula, 
arte culta e arte popular [...]" (EAGLETON, 2011, p. 75). Ora, não haverá mais fronteiras entre o belo e o vulgar?

Essa nova busca por experiências estéticas focadas apenas em si mesmas se tornou marco histórico do movimento romântico, criando uma ideia de subjetivismo radical (HARVEY, 2012). Trata-se de uma espécie de um devir individual e desenfreado, uma autorrealização pessoal e nada que se aproxime de uma intencionalidade filosófica conhecida pela possibilidade de elevar o caráter de indivíduos, primeiro tocando suas almas com a beleza, abrindo assim as portas para o conhecimento (SCHILLER, 2002). Em outras palavras, sustento que a arte deva prezar pelo belo produzindo o bom.

$\mathrm{O}$ último relato ressalta o ceticismo. Lembro-me de divulgar a um determinado grupo acadêmico alguns seminários de História da Ciência ocorridos em nossa universidade e que foram ministrados por pesquisadores oriundos de instituições internacionais, como Oxford e Wisconsin. Em síntese, os seminários abordavam o tema Ciência e Religião, afirmando que o discurso religioso na Idade Média também colaborou com o discurso científico, não apenas contradizendo-o ou acusando-o de "bruxarias" como aprendemos costumeiramente desde o Ensino Médio escolar (NUMBERS, 2009). No diálogo, fui ironizado por alguns intelectuais nietzschianos: "é... legal... mas é só mais uma construção, né??". O segundo questionou: "Idade Média e Religião apoiando a Ciência? Duvido! De Santo Agostinho pra frente não tem nada... e se tiver pode-se desconstruir com facilidade". Causou-me profunda estranheza a "certeza" com a qual julgavam as pesquisas apresentadas no seminário sem as terem assistido.

Diante das falas, perguntei-me: para quê pensar, teorizar, pesquisar, escrever, dialogar, citar, colocar referências e publicar na pós-modernidade? Não parece mais necessário, pois suas epistemologias céticas já definiram que tudo é mentira, desqualificando qualquer investigação antes mesmo de analisar suas fontes. Serão esses os pesquisadores descendentes de Nietzsche? Harvey (2012, p. 315) é enfático:

Esse aspecto do pós-modernismo foi reforçado pelas atividades dos desconstrucionistas. Em sua suspeita de toda a narrativa que aspire a ter coerência, e em seu açodamento de desconstruir qualquer coisa que ao menos pareça uma metateoria, eles solaparam todas as proposições básicas. [...] Assim fazendo, produziu[-se] uma condição de niilismo que preparou o terreno para o ressurgimento de uma política carismática e de proposições ainda mais simplistas do que as que tinham sido desconstruídas.

Moreira (2008) destaca que as concepções pós-modernas de pensamento tendem a desafiar interesses de grupos dominantes. Assim, sustento que elas possam contribuir para mitigar coerções 
e autoritarismos. Mas nos relatos em destaque, percebemos apenas ironia e superficialidade, as quais se constituem nas características mais fundamentais do relativismo celebratório. Parece-me plausível acreditar que o foco na desconstrução seja passível de obscurecer a crítica dos indivíduos, inclusive sobre si mesmos, desvalorizando pesquisa, esforço, abnegação, racionalidade. Tende-se a estimular individualismos, ímpetos e desejos, argumentando que isso é uma ideia ética amparada pela "política do devir", a qual bastaria para justificar as diferenças. No que chamam de uma suposta transição de um mundo moderno para o pós-moderno, o "Penso, logo: existo" parece ser substituído por um confortável "Desejo, logo: posso", um relativismo que a meu ver, anula entendimentos e consensos sobre respeito e alteridade. Observo uma distorção da ética.

\section{ALGUNS EXEMPLOS DE FRAGMENTOS TEÓRICOS DA LITERATURA RELATIVISTA E AS CARACTERÍSTICAS “CONCRETAS” DO PENSAMENTO PÓS-MODERNO}

O primeiro fragmento que destaco trata do texto de Suely Rolnik (1993, p. 7), pesquisadora dedicada à produção intelectual de Deleuze e Guatarri. De fato, seus textos me chamam muito a atenção devido a forte crítica à lógica, por isso mantive o recorte demasiado longo, o qual suponho merecer a atenção do leitor:

$[\ldots]$ às vezes tendemos a nos perder das marcas, a ficar fazendo jogos obsessivos no vazio onde o rigor passa a ser de ordem exclusivamente lógica. Quando é assim, escrevemos textos sem o brilho de uma vitalidade, na medida em que são textos que não encarnam marca alguma, e que na melhor das hipóteses têm um brilho puramente intelectual, de inteligência e/ou erudição. Em geral isto acontece quando não estamos suportando o estranhamento provocado pelas marcas, quando sua trepidação tornou-se infernal, e então para nos proteger, nos aboletamos no oco de um conceito neutro e gratuito na medida em que não nasceu de uma violência, ou ficamos como zumbis zanzando no exercício clean de um quebra-cabeça de charadas lógicas. O rigor nessas ocasiões parece estar a serviço de uma permanência no campo da representação como defesa fóbica contra o desassossego trazido por alguma marca, pela solidão de sua singularidade e pelo medo de nos apresentarmos como encarnação desta singularidade solitária. E quanto mais brilhante o texto em inteligência e erudição, quando é só este seu brilho, pior é, pois mais nos impede de ver que estamos fugindo da raia, a raia da vida e do tempo a exigir nosso esforço de criação.

O fragmento acima não parece exemplificar tolerância e respeito às questões de alteridade, algo tão defendido nos escritos das teorias "celebratórias" e nos estudos sobre diferenças. Ao ler, questionei ainda se inteligência e criatividade são coisas muito 
distintas e desvinculadas. Ora, não haverá relação entre criatividade e racionalidade na erudição do estilo da autora? Pergunto, como Eagleton (2011): um discurso que ataca a própria intelectualidade pode vir a ser intelectualmente legítimo?

Em outro polêmico texto ${ }^{5}$, intitulado "Ninguém é deleuziano" (o qual foi publicado com títulos distintos em vários veículos), a mesma autora (ROLNIK, 1995, p. 4, grifo meu) argumentou sobre a morte de Gilles Deleuze:

Mas quando tudo se tornou definitivamente impossível, ele escolheu fazer o que
parece sempre ter feito em sua vida e que, em todo caso, sempre defendeu em
sua obra: enfrentar as diferenças que se apresentam e, por mais insuportáveis que
sejam, encaminhar a existência na direção que elas apontam. Haverá diferença mais
insuportável e que requer maior coragem de enfrentamento do que a morte?
Deleuze teve a coragem de afirmar a vida até neste momento extremo de seu fim.

O trecho destacado "põe em xeque" a racionalidade dos seus interlocutores. Advogo que a declaração seja irresponsável e convido meu leitor a ser radicalmente prático por um momento. Refletindo sobre o tema "suicídio" na escola (ou mesmo no ensino superior), poderíamos, na condição de professores, sustentar aos discentes que um suicídio pode ser um ato de coragem? Quais poderiam ser as consequências de tal atitude, por mais abstrata que venha a ser a discussão? Assim, apresento a lucidez de Gramsci (1986, p. 38), definindo que a tarefa da Educação consiste em

acostumar a raciocinar, a pensar abstrata e esquematicamente, mantendo, ao mesmo tempo, a capacidade de sair da abstração e mergulhar na vida real e imediata, a observar em cada fato ou dado o que é geral e o que é particular, a distinguir o conceito do exemplo particular.

Observemos agora um fragmento (citado para debate em um curso de pós-graduação) do seguinte texto de Daniel Lins ${ }^{6}$, pesquisador contemporâneo e conhecido nos debates educacionais sobre a filosofia pós-moderna:

Com Deleuze, pensar torna-se um esporte, entretanto, se o esportista aplica-o, desenvolve também uma ideia do jogo. Praticar um esporte é também jogar, é acolher um pensamento como transversalidade do esporte. [...] Deleuze, filósofo surfista da imanência? [...] O filósofo, enfermo, cansado foi, discretamente, à "Noite do escorrego", "La nuit de la glisse". Alguns dias depois, os surfistas receberam uma mensagem de Gilles Deleuze: [...]. Estou certo de que a filosofia é concernida pelo surf'. O surf é a vida em sensações cósmicas [...]. (grifos meus)

A tagarelice pós-moderna, destacada por Anderson (1999), é mais uma vez identificada. O autor afirma que a circulação das ideias "pós" 
pelo corpo social, tipicamente, não depende da sua coerência, sendo que sua influência ideológica permanece considerável e de modo algum confinada apenas à vida universitária, mas permeando a cultura popular em geral. Decerto que nenhum intelectual dos estudos críticos escreveria um artigo acadêmico sobre "fenomenologia na praia" e muito menos atribuiria a Paulo Freire um título de "educador surfista da imanência".

Neste contexto reflexivo e de elevada abstração, eu não poderia deixar de acrescentar a atitude de um intelectual nietzschiano de escol e conhecido por todos no campo educacional, e que parece muito pertinente ao debate. Refiro-me a Tomaz Tadeu da Silva - antes marxista, hoje nietzschiano - que ironizou seu próprio currículo, sua própria história, sua própria identidade, em recente reedição de obra acadêmica (MOREIRA, SILVA, 2011). Em suas palavras, Silva "Autodefine-se como ex-seminarista, ex-católico, ex-marxista, ex-marido, ex-tudo. Só não é, por enquanto, ex-tradutor: traduzir literatura é a sua atividade atual" (grifo meu). Que quis afirmar o autor? Será um membro da "nova esquerda" destacada por Harvey (2012)? Como admirador de seus trabalhos anteriores, questiono o sarcasmo que transborda de suas palavras contra os grupos dos quais ele já fez parte. É isso o que sobra de sua experiência e elevada condição intelectual, e que foi apresentada ao público acadêmico nas últimas décadas por meio de textos significativos para o campo da Educação? Observo mais um resultado estranho e niilista do legado de Nietzsche. Estamos, doravante e lamentavelmente, privados de novas produções críticas de Silva? Aniquilam-se as diferenças e as diversidades em sua fala. Teria ainda um devir "ex-sujeito"? Ora, se a subjetividade pode ser compreendida como uma condição de ser um fundamento de si mesmo (COELHO, 2013), a resposta para esta última pergunta seria um inequívoco "sim".

Isso posto, destaco algumas características do pensamento pós-moderno, sustentadas pela lógica de Moreira (2008): (1) a suspeita das crenças na tradição filosófica e na razão, desafiando os interesses de grupos dominantes; (2) a cultura de "massa" não mais é vista como alienante, mas como algo que pertence à cultura e que precisa ser considerada; (3) rejeição a uma visão de futuro na qual a escola seja capaz de construir uma sociedade mais igualitária; (4) desconsideração sobre o conceito de ideologia por associá-lo às subjetividades, assim como de discursos independentes da posição de seus emissores e acima dos interesses parciais dos diferentes grupos; (5) o conhecimento é visto como mero discurso, não considerando a questão da validade, o que permite uma posição relativista mais "forte"; 
(6) acredita numa consciência fragmentada, parcial e incompleta. Portanto, a educação como uma "conscientização" não seria válida, como uma substituição de "ingenuidade" por "criticismo".

Por outro lado, algumas implicações podem ser consideradas, ainda sustentadas pelo autor: (1) o foco no "relativismo" pode impedir a percepção do indivíduo sobre o sentido da dinâmica social e global; (2) o excesso de preocupação com o "discurso" pode ser passível de obscurecer as estruturas sociais concretas e seus efeitos reais na vida das pessoas; e (3) desacreditar em um sujeito capaz de atingir uma consciência mais centrada pode levar tanto a uma atitude menos arrogante, como a uma atitude cínica que impossibilite a crítica e a transformação do que é opressivo e que existe em algumas teorias e práticas educacionais.

Apoiado nessa perspectiva criteriosa, sustento que o advento do "relativismo" levou parte dos pesquisadores educacionais a negligenciar a análise dos signos obscuros da modernidade, o que era uma das tarefas básicas do estruturalismo e dos estudos críticos. Parece diluído o questionamento de suas consequências problemáticas para se supor, unicamente, que a causa de todas elas seria a própria racionalidade, instigando o seu completo aborto. Um exemplo clássico seriam as excessivas abstrações da filosofia de Deleuze $(1987 ; 1988)$, tendo Nietzsche por mentor, as quais parecem trair a ele mesmo quando acabam por demarcar locais - fronteiras filosóficas espaço-temporais - ao tentar explicar que "a inteligência só é boa quando vem depois" para assessorar a criação de um corpo conceitual. Como isso será possível? Existirá um "território", uma espécie de "limbo corporal" onde o intelecto e o sensível estejam completamente ausentes no ser humano? A existência de um local/tempo demarcado, por si mesma, já seria uma incoerência na própria teoria pós-moderna. Mas como Anderson (1999, p. 134) ressalta as conclusões de Eagleton, "a ilusão, e não o equilíbrio, constitui a base do pós-moderno".

\section{CONSIDERACְ̃̃ES FINAIS}

Tendo já esclarecido meu ponto de vista, sustento não haver problema na racionalidade "gerada no ventre" Renascentista e "cuidada no berço" Iluminista, mas sim no esquecimento do "outro" por parte daqueles que a assumem de forma insensível. Uma "frieza" que se desenvolveu em sua "adolescência" impetuosa no convívio com a lógica capitalista moderna. Suponho, pois, estarmos vivendo uma fase "adulta" da modernidade, mais reflexiva, a qual ainda tem maior "maturidade" por alcançar. 
Considerando a natureza instintiva que ainda possuímos e que ainda podemos apresentar enquanto indivíduos egoístas, acredito que negar a racionalidade seja um caminho perigoso. Ora, se abandonarmos a potencialidade da busca por uma condição racional de centralidade (ou equilíbrio), ainda que difíceis diante das adversidades e incertezas do mundo contemporâneo, nos sobrariam, em síntese, três possibilidades: (1) ou caminharíamos para um pieguismo acrítico, sem critérios de convívio em qualquer campo social; (2) ou viveríamos inseridos num contexto de cinismo insensível, intensificando o isolamento de indivíduos e/ou grupos; (3) ou daríamos vazão a um devir destrutivo (do outro), já que as consequências oriundas de um livre-arbítrio desmedido e "celebratório" poderiam sempre ser "relativizadas". De fato, tais possibilidades niilistas me parecem atravessadas subjetivamente pela intolerância. Será isso que se espera de uma sociedade pós-moderna?

Toda a análise me levou a considerar que alguns valores defendidos recentemente na literatura em Educação (MCLAREN, 1993; MOREIRA, 2008; SANTOS, 2010), com destaque para a solidariedade e o próprio respeito às diferenças, nada significariam na pós-modernidade senão uma hipocrisia padronizada. Isso seria um reflexo inegável do legado nietzschiano e, no meu entendimento, o de implicação social mais traumática. Ora, precisamos sim de teorias que expressem a diferença, mas o que destaquei nas experiências descritas me pareceu muito mais uma tentativa de "homogeneização niilista". Se os teóricos pós-modernos tentaram valorizar "diferenças", o que conseguiram mesmo foi deixar mais sensível a própria "indiferença", presente em suas práticas e discursos. Sustento, pois, que busquemos compreender como as relações, nas quais as diferenças são constituídas, operam como parte de um conjunto amplo de práticas sociais, políticas, culturais e pedagógicas. Considerar a ideia de "diferença" como algo isolado de sua materialidade histórica e política, é negar sua integração, sua constituição na totalidade como uma manifestação do real.

Mas serão a centralidade, o equilíbrio e o consenso, utopias inatingíveis? Se realmente forem, fiquemos com a ideia de sua perseguição. Se há mais de um século, Durkheim nos mostrava que precisávamos colaborar mutuamente por meio da divisão do trabalho social, eu pergunto: haverá alguma forma de avançarmos socialmente hoje - mitigando as opressões em um mundo no qual não podemos confiar plenamente uns nos outros - que não seja por meio da elaboração (e negociação) de políticas públicas, isto é, de novas "narrativas" que são baseadas, objetiva e subjetivamente, na análise crítica de nossa própria história, ou ainda, pela própria 
investigação científica? Será demasiado argumentar sobre o excesso de abstração filosófica e sobre a intencionalidade niilista, propostas pelo pensamento "pós", em detrimento de soluções para tantos problemas sociais que reclamam viabilidade e urgência?

Antes de finalizar, realizo última anotação, ainda que pareça perversa. A ideia pós-moderna de inexistência da história, a qual também vinculei ao radicalismo do movimento de diáspora da (nova) esquerda política, comemora um futuro semelhante ao presente, mas ironicamente, parece ignorar que o presente não é igual ao passado. Se realmente um futuro político pudesse mesmo ser vislumbrado a partir desse contexto, ele chamar-se-ia fascismo (EAGLETON, 1998), mesmo que entendido, paradoxalmente, como pensamento próximo da extrema direita no espectro político contemporâneo. De fato, tanto os pós-modernos da esquerda quanto os neoliberais da direita possuem aproximações, quero dizer, suspeitam de normas, valores e hierarquias, mas a diferença é que a direita radical é consistente e sempre assumiu isso em nome do mercado. Hoje, a ideia é estampada na sua mais nova forma, conhecida por Terceira $\mathrm{Via}^{7}$. A esquerda, por sua vez, não assume que possui suas próprias normas, valores e hierarquias, parece não admitir a ancoragem cultural ao capital... e subscreve-se intelectualmente, de forma sibilina, nos variados rótulos "pós", alguns dos quais já vistos como coisa do passado (LIPOVETSKY, 1989; EAGLETON, 1998; 2011), e talvez até enterrados nos escombros do Muro de Berlim.

Não há uma sociedade nova, pois o "pós" é uma resposta lógica do capitalismo avançado, com a esfera cultural visivelmente ampliada e a estética sensivelmente aguçada. A cultura ocupou a base, a cultura extinguiu o sujeito e o consumo nos tem dominado. Mesmo sem negar a sociedade como tal, me parece evidente que os pós-modernos negam seu poder como coletividade corporificada, o que me remete a um pensamento oposto sobre o quanto um ser humano realmente depende do outro, isto é, trato aqui da solidariedade orgânica tão ressaltada na sociologia (DURKHEIM, 1999). Sim, reconheço a dificuldade de aplicar a teoria de Durkheim na contemporaneidade, entretanto, suponho que ele não deixou de ter muitas coisas a nos ensinar.

Por isso, termino argumentando com sua famosa comparação orgânica da sociedade com um corpo biológico, no qual cada órgão deve bem funcionar para que esse corpo possa ter saúde para produzir para si e para os outros. Quero dizer que, tanto os indivíduos, como as instituições - mesmo com suas novas formas contemporâneas devem continuar a buscar o seu melhor equilíbrio, proporcionando assim, maior segurança ao corpo social. 
Entretanto, se temos hoje um relativismo doentio que enfraquece valores sociais arduamente conquistados, devemos sim nos apropriar de anticorpos, de "vacinas contra o devir(us)" da insistente "celebração", ufanista, ardilosa e caprichosamente carismática, que busca apenas desconstruir gratuitamente. Essas "vacinas", as quais posso nomear por ética e razão, ou ainda, se preferir o leitor, por sensibilidade e racionalidade, devem estar integradas, o quanto mais possível coesas, constituindo o sujeito no bom combate interno às suas idiossincrasias instintivas e egoístas.

Por fim, e se questionar é uma das ações mais fundamentais da condição humana, encerro com uma pergunta aos meus interlocutores, em especial, aos professores: nesse oceano contemporâneo, de calmarias e tempestades, de solidariedade e egoísmo, de certezas e contingências, seguramos com determinação no leme ou nos entregamos à deriva das "correntes"?

\section{REFERÊNCIAS}

ANDERSON, Perry. As origens da pós-modernidade. Rio de Janeiro: JZE, 1999.

BAUMAN, Zygmunt. Modernidade líquida. Rio de Janeiro: JZE, 2001.

COELHO, Humberto Schubert. A insuficiência do sujeito na metafísica da subjetividade. Theologica, Braga, v. 48, n. 1, p. 157-169, 2013.

DELEUZE, Gilles. Proust e os signos. Rio de Janeiro, Forense Universitária, 1987.

DELEUZE, Gilles. Diferença e repetição. 2a ed. Rio de Janeiro: Graal, 1988.

DURKHEIM, Émile. Da divisão do trabalho social. Tradução de Eduardo Brandão. $2^{\mathrm{a}}$ ed. São Paulo: Martins Fontes, 1999.

EAGLETON, Terry. As ilusões do pós-modernismo. Rio de Janeiro: Zahar, 1998.

EAGLETON, Terry. Depois da teoria: um olhar sobre os Estudos Culturais e o pósmodernismo. $3^{\text {a }}$ ed. Rio de Janeiro: Civilização Brasileira, 2011.

GRAMSCI, Antonio. Selections from the Prison Notebooks. London: Lawrence \& Wishart, 1986. HARVEY, David. Condição pós-moderna. 23ª ed. São Paulo: Edições Loyola, 2012.

LIPOVETSKY, Giles. A era do vazio: ensaio sobre o individualismo contemporâneo. Lisboa: Antropos, 1989.

LYOTARD, Jean-François. Lotta Poetica, série 3, v. 1, n.1, jan. 1987.

MARTINS, André Silva. A direita para o social: a educação da sociabilidade no Brasil contemporâneo. Juiz de Fora: UFJF, 2009.

MCLAREN, Peter. Pós-modernismo, pós-colonialismo e pedagogia. In: SILVA, Tomaz Tadeu da. (Org.). Teoria educacional crítica em tempos pós-modernos. Porto Alegre: Artes Médicas, 1993.

MOREIRA, Antonio Flavio Barbosa. Currículo: questões atuais. 14ª ed. Campinas, SP: Papirus, 2008. 
MOREIRA, Antonio Flavio Barbosa. A qualidade e o currículo na escola básica brasileira. In: PARAÍSO. M. A. (Org.). Antonio Flavio Barbosa Moreira: pesquisador em currículo. Belo Horizonte: Autêntica, 2010. (Coleção Perfis da Educação).

MOREIRA, Antonio Flavio Barbosa; SILVA, Tomaz Tadeu da. Currículo, cultura e sociedade. $12^{\mathrm{a}}$ ed. São Paulo: Cortez, 2011.

NUMBERS, Ronald. Galileo goes to jail and other myths about Science and Religion. Ed. Cambridge, MA: Harvard University Press, 2009.

ROLNIK, S. Pensamento, corpo e devir: uma perspectiva ético-estética/política no trabalho acadêmico. Cadernos de Subjetividade, São Paulo, v. 1, n. 2, p. 241-251, 1993.

SANTOS, Boaventura de Sousa Santos. Pela mão de Alice: o social e o político na pósmodernidade. $13^{a}$ ed. São Paulo: Cortez, 2010.

SCHILLER, Friedrich. A educação estética do homem. São Paulo: Iluminuras, 2002.

YOUNG, Michael. O futuro da educação em uma sociedade do conhecimento: o argumento radical em defesa de um currículo centrado em disciplinas. Revista Brasileira de Educação, Rio de Janeiro, v. 16, n. 48, p. 609-623, 2011.

\section{NOTAS}

${ }^{1}$ Mesmo reconhecendo que Foucault não tenha assumido um rótulo "pós-moderno", devo citá-lo aqui como um pensador significativo desse grupo. De fato, parece não haver uma classificação epistemológica para Foucault, mas suas ideias nasceram da crítica à racionalidade moderna. Para maiores detalhes, ver Eagleton (2011).

${ }^{2}$ Convém ressaltar que autores como Raymond Williams, ou mesmo Marshall Berman, são representantes da "nova esquerda", mas também são autores de trabalhos contra os "pósmodernos" (os "novos conformistas"). Berman chega a ser tido por muitos como um "pósmoderno", mas é um defensor radical da modernidade como uma experiência em expansão, tendo refletido sobre uma série de questões, como cultura e arte, que ampliam o horizonte das esquerdas em relação aos elementos constitutivos da modernidade.

${ }^{3} \mathrm{O}$ próprio Lyotard veio a reconhecer que sua obra mais famosa, $A$ condição pós-moderna, referia-se ao destino epistemológico das ciências naturais, sobre as quais ele mesmo apresentava um conhecimento limitado. Em suas palavras: "Construí histórias [...] é tudo um pouco de paródia. É simplesmente o pior dos meus livros, que são quase todos ruins [...]”.

${ }^{4}$ Refiro-me aos clássicos filmes de ficção científica das décadas de 1960 até meados de 1990, muitos dos quais marcados por uma visão hedionda e fracassada da humanidade já num futuro próximo. Parece-me inegável que o campo cinematográfico colaborou muito na construção de identidades e subjetividades ao longo do século XX. A título de ilustração, destaco o intrigante clássico do cinema cult, "Blade Runner: o caçador de androides". Para Harvey (2012), o filme reúne inúmeras características "pós-modernas".

${ }^{5}$ Entrevista a Lira Neto e Silvio Gadelha, publicada com este título in O Povo, Caderno Sábado: 06. Fortaleza, 18/11/95; com o título "A inteligência vem sempre depois" in Zero Hora, Caderno de Cultura. Porto Alegre, 09/12/95; p. 8; e com o título "O filósofo inclassificável" in $A$ Tarde, Caderno Cultural: 02-03. Salvador, 09/12/95.

${ }^{6}$ Sociólogo, filósofo e psicanalista, com doutorado em Sociologia - Université de Paris VII - Université Denis Diderot. Texto completo em: < http://overtebral.blogspot.com. br/2009/11/deleuze-surfista-da-imanencia.html>.

${ }^{7}$ Para maiores detalhes, ver Martins (2009). 
Recebido: 21/06/2014

Aprovado: 17/04/2015

Contato:

Cláudio Pellini Vargas

Universidade Federal de Juiz de Fora

Rua José Lourenço Kelmer, s/n

Campus Universitário. Bairro São Pedro

Juiz de Fora $|\mathrm{MG}|$ Brasil

CEP 36.036-900 